\title{
Effects Of The ACA's Health Insurance Marketplaces On The Previously Uninsured: A Quasi-Experimental Analysis
}

\section{Citation}

Goldman, Anna L., Danny McCormick, Jennifer S. Haas, and Benjamin D. Sommers. 2018. "Effects Of The ACA's Health Insurance Marketplaces On The Previously Uninsured: A QuasiExperimental Analysis." Health Affairs 37 (4) (April): 591-599. doi:10.1377/hlthaff.2017.1390.

\section{Published Version}

doi:10.1377/hlthaff.2017.1390

\section{Permanent link}

http://nrs.harvard.edu/urn-3:HUL.InstRepos:37136775

\section{Terms of Use}

This article was downloaded from Harvard University's DASH repository, and is made available under the terms and conditions applicable to Open Access Policy Articles, as set forth at http:// nrs.harvard.edu/urn-3:HUL.InstRepos:dash.current.terms-of-use\#OAP

\section{Share Your Story}

The Harvard community has made this article openly available.

Please share how this access benefits you. Submit a story.

\section{Accessibility}


Effects of the ACA's Health Insurance Marketplaces on the Previously-Uninsured: A Quasi-Experimental Analysis

\author{
Anna L. Goldman, MD, MPA ${ }^{1,2}$ \\ Danny McCormick, MD, MPH ${ }^{1,2}$ \\ Jennifer S. Haas, MD, MPH ${ }^{2,3}$ \\ Benjamin D. Sommers, MD, $\mathrm{PhD}^{2,3,4}$
}

Version Date: December 19, 2017

\footnotetext{
${ }^{1}$ Cambridge Health Alliance

${ }^{2}$ Harvard Medical School

${ }^{3}$ Department of General Internal Medicine, Brigham and Women's Hospital

${ }^{4}$ Department of Health Policy and Management, Harvard T.H. Chan School of Public Health
} 


\begin{abstract}
:
Descriptive studies have suggested that the Affordable Care Act's (ACA) health insurance Marketplaces improved access to care. However, no quasi-experimental evidence is currently available to support these findings. We use longitudinal survey data to compare previouslyuninsured adults to adults who had employer-sponsored insurance (ESI) prior to the ACA, in the income range eligible for subsidized Marketplace coverage (138-400\% of poverty). Among the previously-uninsured group, the ACA led to a significant decline in the uninsurance rate $(-10.8$ percentage points), decreased barriers to medical care, increased use of outpatient services and prescriptions drugs, and increased identification of high blood pressure, compared to a control group with stable ESI. Changes were largest among those with incomes between 138-250\% of poverty, who were eligible for the ACA's cost-sharing reductions. Our quasi-experimental approach provides rigorous new evidence that the ACA's Marketplaces led to improvements in several important health care outcomes, particularly among lower-income adults.
\end{abstract}




\section{INTRODUCTION}

Evidence on the effects of the Affordable Care Act (ACA) continues to grow, even as the likely elimination of the individual mandate penalty and ongoing political debate has made its future impact uncertain. Numerous studies have examined impacts of the Medicaid expansion,(1-3) whereas less research has focused on the ACA's health insurance Marketplaces.

The Marketplaces offer subsidized coverage to families with incomes between $138-400 \%$ of poverty (100-400\% in states that did not expand Medicaid), and provide cost-sharing reductions for those with incomes below 250\%. 6.7 million people purchased insurance through ACA Marketplaces in the first open enrollment period spanning from October of 2013 to March of 2014,(4) and 10.3 million had done so by 2017.(5) One study estimated that subsidized Marketplace coverage accounted for $40 \%$ of the ACA's reduction in the uninsured rate.(6)

The Marketplaces were designed to improve affordability and accessibility of health care for low- and middle-income populations. In addition to premium and cost-sharing subsidies, the ACA also abolished annual and lifetime limits, mandated that insurance plans cover a set of “essential health benefits," and outlawed pre-existing condition exclusions.(7) Observational studies have shown substantial increases in coverage among those eligible for Marketplace subsidies,(8-10) increased likelihood of having a usual source of care and access to medications,(11) and increased rates of blood pressure screening.(12, 13) However, to our knowledge, there has been no quasi-experimental evidence on the Marketplaces' impact. Rigorous evaluations of changes in coverage and access in the Marketplace-eligible income range are needed, particularly because higher cost-sharing requirements(14) and narrow networks in Marketplace plans(15) may limit the generalizability of evidence from the ACA's Medicaid expansion. Finally, observational analyses of people gaining Marketplace coverage 
that do not include a control group run the risk of multiple forms of bias - including secular trends in health outcomes, the economic recovery, and selective enrollment among a subset of eligible applicants.

Our study assessed the impact of newly-available Marketplace coverage on previouslyuninsured non-elderly adults who became eligible for subsidized Marketplace plans in 2014. Using longitudinal survey data, we performed a difference-in-differences analysis comparing health and spending outcomes among those who were uninsured prior the ACA to a cohort of adults with stable employer-sponsored insurance in the income range eligible for subsidized Marketplace coverage.

\section{METHODS}

Data: We analyzed data from the nationally-representative Medical Expenditure Panel Survey (MEPS). Data is collected for each member of surveyed households over a two-year period and is available in two-year, longitudinal datasets (for simplicity, we refer below to the first and second years of data as Year 1 and Year 2 for each observation).(16) We used three longitudinal data sets: 2011-2012; 2012-2013; and 2013-2014 (Appendix A). We began our study period in 2011 since earlier datasets would be potentially subject to changes related to the Great Recession, as well as the immediate effects of the ACA's dependent coverage provision, which took effect beginning in 2010. The 2013-2014 data set captures the implementation of major ACA policies on January 1, 2014. The 2013-2014 panel was the cohort in which the intervention took place, the "ACA-affected cohort," while the panels from 2011-2012 and 20122013 were combined to form a pre-ACA cohort.

\section{Study Design and Sample:}


Our study used a difference-in-differences analysis, measuring changes in health insurance coverage, access to care, utilization, and costs before and after 2014 in an intervention group compared to a control group.

Our intervention group was comprised of adults aged 18-63 with Year 1 family incomes between 138 and $400 \%$ of the Federal Poverty Level (FPL), who were uninsured for 6 months or more in Year 1. Family income was defined based on concept of the health-insurance unit (an adult, his/her spouse, and any dependent children). Most individuals in this group (subject to the limitations discussed below) became eligible to purchase premium-subsidized insurance on state health insurance Marketplaces in 2014, and those with incomes below 250\% also qualified for cost-sharing reductions. We chose six months of uninsurance as our cut-off to capture the longer-term uninsured population, as opposed to individuals who had brief gaps in coverage due to job changes or temporary fluctuations in income.

The control group consisted of non-elderly adults with incomes between $138-400 \%$ of poverty who were insured with employer-sponsored insurance (ESI) for all twelve months of Year 1. Although there is no perfect control group for the creation of the ACA Marketplaces, previous research demonstrates that the ACA had little detectable effects on ESI, indicating that this group was largely insulated from changes affecting our treatment group,(17-19) making it a useful comparator to account for potential secular trends in the economy and the health care system.

\section{Outcome Variables:}

Our sample was defined based on Year 1 features (age, income, and insurance status). All outcome measures were drawn from Year 2 of the datasets. 
Our primary coverage outcome was health insurance status as of the last month of Year 2. Insurance type is self-reported in the MEPS. Categories of insurance included private employersponsored insurance; non-group private insurance (including Marketplace coverage); Medicaid; and uninsured. As a secondary outcome, we also measured the total number of insured months in Year 2.

Access to care outcomes (again based on Year 2) were self-reported inability to access medical care; delays in obtaining prescription medications; and access to a usual source of care. Utilization measures were Year 2 receipt of a preventive health visit; number of outpatient visits; number of ER visits; number of prescription medications used (including refills); presence of any inpatient admission; receipt of a blood pressure check; and laboratory testing for cholesterol levels. We also assessed changes in prevalence of year 2 diagnosis rates of several common chronic conditions: hypertension, high cholesterol, and diabetes.

Cost-related outcomes were Year 2 total spending and out-of-pocket spending. Total spending is the sum of expenditures by all payers, including out-of-pocket payments, for all health care services excluding over-the-counter medication.(20) Out-of-pocket spending includes all payments made by individuals for outpatient visits, inpatient admissions, emergency room visits, and prescription drugs.(21) MEPS cost data are independently-verified whenever possible with providers of medical services and pharmacies.(16, 22) To account for the skewed distribution of spending data, we analyzed these outcomes with a two-stage model. First, we modeled changes in the proportion of those with any health expenses, and second, we analyzed changes in the logarithm of spending among those with any expenditures. All spending figures were adjusted to 2014 dollars using the consumer price index.(23) 


\section{Statistical Analysis:}

We used linear regression models for both binary and non-binary outcomes for ease of interpretation.(24) Our models adjusted for key demographic characteristics and economic indicators (all from Year 1) including age, sex, race, region, marital status, family size, birthplace outside the U.S., family income, and employment status. All models included two binary indicators: previously-uninsured (intervention) vs. previously-insured via stable ESI (control) group; and pre- vs. post-ACA cohort. The interaction term between these two variables yielded our difference-in-difference estimate.

In a subgroup analysis, we divided our study population by income: a low-income group (family income $138-250 \%$ of poverty), which was eligible for both premium subsidies and costsharing reductions through Marketplace plans, and a middle-income group (251-400\% of poverty), eligible only for premium-cost assistance.

Our primary analysis defined income based on the health insurance unit, but we also conducted a sensitivity analysis using the less-restrictive MEPS definition for family income.(21)

We tested for diverging trends prior to 2014 for our treatment and control group. This analysis used a placebo difference-in-difference model as if the ACA had been implemented in 2013,(25) comparing study outcomes between the previously-uninsured group and the stable-ESI group in the 2011-2012 vs. the 2012-2013 panel.

All regressions were performed with SAS (Version 9.4) using survey-based procedures that accounted for the complex sample design and weights in the MEPS.

\section{Limitations:}


Our study was subject to several limitations. This study includes only a single year of post-ACA data and therefore captures only the first-year effects of the Marketplaces. The ACA's effects would be expected to increase after the first year given that enrollment continued to rise(26) and recipients would have more time to take advantage of newly-acquired benefits. Changes in some outcomes, especially self-reported health status, may not apparent in the first year.(27) The use of only a single post-ACA year was unavoidable given our study design, which relied on two-year longitudinal data from MEPS and specifically exploited the single cohort that overlapped the launch of the ACA's major policies. We feel that this tradeoff is worthwhile given the strength of our study design compared to prior Marketplace-specific analyses.

Although the MEPS is a relatively large dataset, our inclusion criteria resulted in smaller study sample. This may have limited our power to detect small changes that may be clinically or economically relevant, and also precluded analyzing outcomes that were relevant only to a small subset of our sample, such as mammography or pap smear rates. Additionally, following the majority of studies in the coverage expansion literature (3, 28-31), we did not adjust for multiple comparisons, which may increase the risk of false positives.

The MEPS does not include state identifiers in publicly available files. This prevented us from examining the effects of state-specific programs such as the use of insurance navigators and the impact of state- vs. federally-administered Marketplaces, although this may have been challenging given sample-size limitations. In at least one study, state-administered Marketplaces were shown to be more effective in expanding coverage.(6) Lack of state identifiers also eliminated the possibility of controlling for the effect of Medicaid expansion in some states, which affects the income-range in each state eligible for Marketplace coverage. 
In addition, not all uninsured adults may have been eligible for Marketplace subsidies, either due to immigration status or having an affordable offer of ESI that they did not accept. Our dataset did not allow us to evaluate these factors; if anything, this would lead our analysis to underestimate the changes in coverage and access among the truly eligible population.

Finally, as stated earlier, no perfect control group exists for the ACA's Marketplace, given that this policy was implemented on a national level at a single point in time. Many observed differences exist between our intervention and control groups, as well as potentially unobservable differences. However, the validity of our difference-in-difference study design does not depend on the balance of characteristics between the study groups, but rather on the assumption that trends would have been comparable for both study groups in the absence of the policy change. The placebo tests of the pre-ACA period provide support for this assumption. The use of our control group strengthens the analysis by reducing bias from mean reversion and secular trends in our estimates of Marketplace effects on the previously-uninsured.

\section{RESULTS}

Our study population included 9,653 adults. 5,770 had continuous coverage with ESI and 3,883 were uninsured for six months or more in Year 1 (Exhibit 1). Compared to the stable ESI group (control group), the uninsured group (treatment group) was younger and more likely to be male, Hispanic, and live in the South or West. Mean family income was lower in the treatment group, which was also somewhat less likely to be employed prior to the ACA - though the majority of adults in both groups were employed ( $82.7 \%$ vs. $86.9 \%)$.

Exhibit 2 presents changes in health insurance before and after the ACA for each study group. Among the treatment group compared to the control group, ACA implementation was 
associated with a large drop in the uninsured rate by the end of Year 2 (-10.8 percentage points, $p<0.001)$. The likelihood of having any private insurance increased by 8.8 percentage points $(p<0.001)$. More specifically, rates of non-group private coverage (including Marketplace plans) increased by 6.0 percentage points $(p<0.001)$, while Medicaid participation increased to a lesser degree $(2.5 \%, p=0.06)$ and ESI enrollment did not increase significantly. In 2014, Marketplace coverage rates were $6.8 \%$ in the treatment group and $1.1 \%$ in the control group.

Exhibit 3 shows monthly rates of non-group private coverage for the treatment and control groups - which demonstrates a sharp rise for the treatment group in the first three months of 2014, while the control group remained relatively constant.

Regression-based difference-in-difference estimates are presented in Exhibit 4, and Appendix C presents plots of several outcomes over time for the treatment vs. control group. The share of previously-uninsured adults reporting that they were unable to get necessary care declined by 1.9 percentage points compared to the control group $(p=0.08)$. There were no significant changes in the probability of delaying prescription medications or having a usual source of care. Among those with any expenditures, total medical spending increased by $14.3 \%$ and out-of-pocket spending increased by $9.7 \%$, but neither estimate reached statistical significance.

The average number of outpatient visits increased by $0.87(p=0.08)$ among the previously-uninsured, compared to the control group. The probability of inpatient admission increased by 2.5 percentage points ( $p=0.04$ ). The number of prescriptions filled increased by 1.82 medications on average $(p=0.05)$. The likelihood of emergency department visits did not change significantly, and neither did preventive visits or self-reported health. The likelihood of 
receiving a diagnosis of hypertension increased by 7 percentage points among the previously uninsured $(p=0.003)$.

Results of a sensitivity analysis using a broader family definition to measure income yielded similar results to our primary analysis (Appendix D). In comparison, the number of previously-uninsured adults reporting that they were unable to get necessary care showed a larger decline $(-2.4$ percentage points, $p=0.03)$ and the number of outpatient visits increased more robustly (1.31 additional visits, $p=0.03)$.

\section{Subgroup analysis:}

Both the low-income group (138-250\% FPL) and the middle-income group (250-400\% FPL) experienced large increases in coverage by the end of Year $2(11.1 \%$ and $13.2 \%$ respectively, both $p<0.01$; Exhibit 4).

Changes in access and utilization were generally larger among the lower-income subgroup than the higher-income subgroup (Exhibit 4), though with some variation across outcomes. For the lower-income group, rates of being unable to access care declined significantly ( -2.7 percentage points, $p=0.05)$ and outpatient utilization increased (1.96 visits, $\mathrm{p}=0.004$ ), compared to the control group. Likelihood of any inpatient admission rose by 3.8 percentage points $(p=0.07)$. The low-income subgroup also showed a large increase in the number of prescription fills (an additional 4.62 per year, $p=0.001$ ) and in the likelihood of hypertension diagnosis $(+6.1$ percentage points, $p=0.06)$. Diagnosis of high cholesterol showed an increase in the low-income subgroup (5.7 percentage points, $p=0.06$ ), which was not evident in the full sample. 
In the higher-income subgroup, previously uninsured adults experienced a decreased likelihood of delaying medications ( -3.3 percentage points, $p=0.03)$ and increased likelihood of hypertension diagnosis ( 7.7 percentage points, $p=0.08$ ). Total medical spending among those with any expenditures also rose in this subgroup $(38.3 \%, p=0.05)$.

\section{Placebo tests:}

Our placebo analysis showed no significant differential changes in the pre-ACA cohort for nearly all study outcomes (Appendix B). Only one outcome — cholesterol screening — showed a difference at $p<0.10$; however, this indicated that the likelihood of screening was decreasing in the pre-ACA period for our treatment group, which would bias us against finding a positive result in this group. Overall, these findings demonstrate comparable pre-ACA trends in outcomes for our treatment and control groups, supporting our difference-in-difference approach.

\section{DISCUSSION}

Using a rich longitudinal national survey, our study offers new evidence on the effect of the ACA's health insurance Marketplaces on subsidy-eligible adults. Insurance coverage increased significantly among previously-uninsured adults, with the majority of growth due to Marketplace coverage. These coverage gains were accompanied by a reduction in barriers to needed care, more outpatient visits, increased inpatient care, and additional use of prescription drugs. We also find an increase in the rates of diagnosis of hypertension. Other outcomes, including out-of-pocket and total spending, did not change. Our findings, detected in the first year after the ACA's implementation, suggest that the Marketplaces are contributing to a broad range of positive effects for previously-uninsured adults. Our analysis of income subgroups 
suggests that improvements in access to care were concentrated among lower-income adults eligible for cost-sharing subsidies.

These results demonstrate that, despite initial challenges in the rollout of the Marketplace, the program was successful in improving coverage among many long-term uninsured adults. However, even after the expansion, more than half of this group remained uninsured at the end of 2014, indicating significant outreach efforts are still needed. Of course, our use of a dataset ending in 2014 means that longer-term gains in coverage are not captured in our results. Of note, only $1 \%$ of the control group was found to have purchased insurance through the Marketplace in 2014, indicating that crowd-out of employer-sponsored insurance by the new Marketplace subsidies was rare, consistent with prior studies of the ACA. $(6,19)$

Our findings of coverage changes are supported by several observational studies that have documented similarly-sized changes in the uninsured rate using the National Health Interview Survey,(9) Health Reform Monitoring Survey,(32) American Community Survey,(6) and Gallup-Healthways Well-Being Index.(33)

We also identified several significant changes in access to care and utilization after coverage expansion, consistent with studies of Medicaid expansion under the ACA. This suggests that despite concerns over potentially high cost-sharing and narrow networks in the ACA,(34)'(15) subsidized Marketplace coverage has still improved care for many middle-income adults. Of note, increases in ESI and Medicaid coverage accounted for just under half of the coverage gains in our previously-uninsured group, indicating that our findings are not solely attributable to new Marketplace coverage. Still, our results are consistent with several observational studies of those in the subsidized Marketplace income range or those who report enrolling in Marketplace plans.(13, 30, 35) 
To our knowledge, no previous work has used quasi-experimental methods to examine changes in health care outcomes among a population of previously uninsured Marketplacesubsidy-eligible adults. Examining longer-term trends in coverage and other health outcomes among these individuals is an area for future research.

Despite finding some beneficial changes in access to care and chronic disease diagnosis, many of our study outcomes - including total spending, preventive health measures, and selfreported health - did not change significantly, in contrast to prior studies of the Medicaid expansion.(1-3) This may reflect the relatively small sample size and that the study only included the first year after ACA implementation; many of those who obtained new insurance in 2014 began coverage midway through the year, leaving limited time to take advantage of new opportunities to seek care. However, it is also possible that Marketplace coverage may be less effective at improving some of these measures than Medicaid, and at least some descriptive evidence suggests that concerns exist about these plans' cost-sharing requirements. For instance, a Kaiser Family Foundation survey found that $36 \%$ of Marketplace enrollees were somewhat or very dissatisfied with the burden of their insurance deductible compared with $25 \%$ of those with ESI coverage.(36) While our study shows this coverage has been beneficial, our post-ACA estimates show that many adults still experience barriers to care, and cost-related challenges may be more common in Marketplace plans with high cost-sharing than in Medicaid, which traditionally has only minimal out-of-pocket payments.(37)

Our subgroup analysis revealed that improvements in access to care was generally larger in the lower-income (138-250\% of poverty) subgroup. This has important implications for the ACA's cost-sharing reductions, which are available to Marketplace enrollees with incomes below $250 \%$ of FPL. Insurers are required to reduce out-of-pocket costs for this group and 
receive payments from the federal government for these expenses; however, the Trump Administration has announced a decision to stop making these payments.(38) Our findings suggest that these cost-sharing subsidies may be an important driver of the positive impacts of Marketplace coverage. However, cost-sharing subsidies are only one potential explanation for the larger effect found in the low-income subgroup. Another is simply that this group had more unmet medical needs prior to the ACA.

\section{Conclusions}

Our study provides some of the first quasi-experimental evidence on the effects of the ACA's Marketplace plans on middle and lower-income nonelderly adults who previously lacked insurance. We identified several notable improvements among previously-uninsured adults in terms of health care access and utilization. These benefits were larger for lower-income adults eligible to receive cost-sharing reductions. The Trump Administration's decision to cease payments for cost-sharing subsidies to insurers, as well as plans to eliminate the individual mandate, could further erode Marketplace coverage and could undo some of these gains. However, despite notable improvements, we also find that many barriers to care remain in this population. Legislative changes to Marketplace plans that increase generosity of subsidies and boost enrollment might produce greater progress on a range of health-care related outcomes. 


\section{References}

1. Wherry LR, Miller S. Early Coverage, Access, Utilization, and Health Effects Associated With the Affordable Care Act Medicaid Expansions: A Quasi-experimental Study. Ann Intern Med. 2016;164(12):795-803.

2. Han X, Nguyen BT, Drope J, Jemal A. Health-Related Outcomes among the Poor: Medicaid Expansion vs. Non-Expansion States. PLoS One. 2015;10(12):e0144429.

3. Cole MB, Galarraga O, Wilson IB, Wright B, Trivedi AN. At Federally Funded Health Centers, Medicaid Expansion Was Associated With Improved Quality Of Care. Health Aff (Millwood). 2017;36(1):40-8.

4. Leavitt LC, C.; Claxton, G. Data Note: How Has the Individual Insurance Market Grown Under the Affordable Care Act? : The Henry J. Kaiser Family Foundation; 2015 May 12, 2015. Contract No.: August 12, 2017.

5. February 2017 Effectuated Enrollment Snapshot: Centers for Medicaid and Medicare Services (CMS); June 12, 2017 [Available from: https://downloads.cms.gov/files/effectuatedenrollment-snapshot-report-06-12-17.pdf.

6. Frean M, Gruber J, Sommers BD. Premium subsidies, the mandate, and Medicaid expansion: Coverage effects of the Affordable Care Act. J Health Econ. 2017;53:72-86.

7. Information on Essential Health Benefits (EHB) Benchmark Plans 2017 [Available from: https://www.cms.gov/cciio/resources/data-resources/ehb.html.

8. Leavitt LC, G.; Daminco, A.; Cox, C. Assessing ACA Marketplace Enrollment: The Henry J. Kaiser Family Foundation; March 4, 2016 [

9. Cohen RM, M.; Zammitti, E. Health Insurance Coverage: Early Release of Estimates From the National Health Interview Survey, 2015. Center for Disease Control; 2016 May 2016.

10. McMorrow SP, D. Insurance Coverage and Access to Care Under the A ordable Care Act. Leonard Davis Institute of Health Economics; 2016 December 8, 2016.

11. Yabroff KR, Kirby J, Zodet M. Association of Insurance Gains and Losses With Access to Prescription Drugs. JAMA Intern Med. 2017.

12. Garfield RY, K. How Does Gaining Coverage Affect People's Lives? Access, Utilization, and Financial Security among Newly Insured Adults. The Henry J. Kaiser Family Foundation; 2015 June 19. 2015.

13. Kirby JB, Vistnes JP. Access To Care Improved For People Who Gained Medicaid Or Marketplace Coverage In 2014. Health Aff (Millwood). 2016;35(10):1830-4.

14. Gunja MC, S.; Doty, M.; Beutel, S. Americans' Experiences with ACA

Marketplace Coverage: Affordability and

Provider Network Satisfaction: Findings from the Commonwealth Fund Affordable Care Act Tracking Survey, February-April 2016. The Commonwealth Fund; 2016 July 7, 2016.

15. Haeder SF, Weimer DL, Mukamel DB. Narrow Networks and the Affordable Care Act. JAMA. 2015;314(7):669-70.

16. MEPS-HC Panel Design and Data Collection Process. Rockville, Md: Agency for Healthcare Research and Quality.

17. Gooptu A, Moriya AS, Simon KI, Sommers BD. Medicaid Expansion Did Not Result In Significant Employment Changes Or Job Reductions In 2014. Health Aff (Millwood). 2016;35(1):111-8.

18. Moriya AS, Selden TM, Simon KI. Little Change Seen In Part-Time Employment As A Result Of The Affordable Care Act. Health Aff (Millwood). 2016;35(1):119-23. 
19. Abraham J, Royalty AB, Drake C. Employer-Sponsored Insurance Offers: Largely Stable In 2014 Following ACA Implementation. Health Aff (Millwood). 2016;35(11):2133-7.

20. 2013 Person Round Plan Public Use File [Available from: https://meps.ahrq.gov/data_stats/download_data/pufs/h111/h111doc.pdf

21. MEPS HC-171: 2014 Full year consolidated data file Rockville, MD: Agency for Healthcare Research and Quality; September 2016 [Available from:

https://meps.ahrq.gov/mepsweb/data stats/download data files detail.jsp?cboPufNumber=HC171.

22. Martin BI, Deyo RA, Mirza SK, Turner JA, Comstock BA, Hollingworth W, et al. Expenditures and health status among adults with back and neck problems. JAMA. 2008;299(6):656-64.

23. Consumer Price Index: Bureau of Labor Statistics; [Available from: https://www.bls.gov/cpi/.

24. Karaca-Mandic P, Norton EC, Dowd B. Interaction terms in nonlinear models. Health services research. 2012;47(1pt1):255-74.

25. Calonico S CM, Farrell M, Titiunik R. Regression Discontinuity Designs Using Covariates. University of Michigan. 2016.

26. Uberoi N, Finegold K, Gee E. Health insurance coverage and the Affordable Care Act, 2010-2016. Washington: Department of Health and Human Services (US), Office of the Assistant Secretary for Planning and Evaluation. 2016;3.

27. Sommers BD, Maylone B, Blendon RJ, Orav EJ, Epstein AM. Three-Year Impacts Of The Affordable Care Act: Improved Medical Care And Health Among Low-Income Adults. Health Aff (Millwood). 2017;36(6):1119-28.

28. Courtemanche CJ, Zapata D. Does universal coverage improve health? The Massachusetts experience. Journal of Policy Analysis and Management. 2014;33(1):36-69.

29. Wees PJ, Zaslavsky AM, Ayanian JZ. Improvements in health status after Massachusetts health care reform. The Milbank Quarterly. 2013;91(4):663-89.

30. Sommers BD, Gunja MZ, Finegold K, Musco T. Changes in self-reported insurance coverage, access to care, and health under the Affordable Care Act. Jama. 2015;314(4):366-74.

31. Abdus S, Mistry KB, Selden TM. Racial and ethnic disparities in services and the Patient Protection and Affordable Care Act. American journal of public health. 2015;105(S5):S668-S75. 32. Long SKK, M.; Kenney, G.M.; Zuckerman, S.; Wissoker, D.; Shartzer, A.; Anderson, N.; Hempstead, K.; Taking Stock: Gains in Health Insurance Coverage under the ACA as of March 2015. Washington, D.C.: Urban Institute; 2015 April 16, 2015.

33. Sommers BD, Musco T, Finegold K, Gunja MZ, Burke A, McDowell AM. Health reform and changes in health insurance coverage in 2014. N Engl J Med. 2014;371(9):867-74.

34. Collins SR, Rasmussen P, Doty M, Beutel S. Too high a price: out-of-pocket health care costs in the United States. Findings from the Commonwealth Fund Health Care Affordability Tracking Survey. September-October 2014. Issue brief (Commonwealth Fund). 2014;29:1-11. 35. Shartzer A, Long SK, Anderson N. Access To Care And Affordability Have Improved Following Affordable Care Act Implementation; Problems Remain. Health Aff (Millwood). 2016;35(1):161-8.

36. Hamel LN, M.; Levitt, L.; Claxton, G.; Brodie, M. Survey of Non-Group Health Insurance Enrollees, Wave 2. The Henry J. Kaiser Family Foundation; 2015 May 21, 2015 
37. Selden TM, Lipton BJ, Decker SL. Medicaid Expansion And Marketplace Eligibility Both Increased Coverage, With Trade-Offs In Access, Affordability. Health Affairs. 2017;36(12):2069-77.

38. Jost TS. Health Affairs Blog [Internet]: Project HOPE. 2017. [August 15, 2017]. 


\section{Exhibit 1: Characteristics of Pre-ACA Cohort}

\begin{tabular}{|c|c|c|c|}
\hline & $\begin{array}{c}\text { Stable ESI Group } \\
(\text { Control })\end{array}$ & $\begin{array}{c}\text { ninsured in Year } 1 \\
\text { Group } \\
\text { (Intervention) }\end{array}$ & \\
\hline Number of subjects & 4047 & 2688 & $* * * *$ \\
\hline Age, mean & 40.7 & 38.8 & \\
\hline \multicolumn{4}{|l|}{$\operatorname{Sex}(\%)$} \\
\hline Female & 53.9 & 42.8 & $* * * *$ \\
\hline Male & 46.1 & 57.2 & \\
\hline \multicolumn{4}{|l|}{ Race/Ethnicity (\%) } \\
\hline Non-Hispanic Black & 11.9 & 11.8 & $* * * *$ \\
\hline Hispanic & 13.7 & 31.2 & \\
\hline Asian & 7.4 & 6.9 & \\
\hline Non-Hispanic White/Other & 67.0 & 50.1 & \\
\hline Family Size, mean & 2.6 & 2.1 & $* * * *$ \\
\hline \multicolumn{4}{|l|}{ Region(\%) } \\
\hline Northeast & 17.1 & 11.9 & $* * * *$ \\
\hline Midwest & 25.9 & 18.2 & \\
\hline South & 35.5 & 43.3 & \\
\hline West & 21.5 & 26.7 & \\
\hline Foreign-Born & 15.4 & 31.3 & $* * * *$ \\
\hline Employed (\%) & 86.9 & 82.7 & $* * * *$ \\
\hline Family Income, mean & $\$ 48,539.00$ & $\$ 35,272.00$ & $* * * *$ \\
\hline
\end{tabular}

Source: Authors analysis of MEPS longitudinal data, 2011-2013.

Notes: The stable ESI group was covered by employer-sponsored insurance for 12 months in Year 1 of the survey. The previously-uninsured group was uninsured for $>$ or $=6$ months in Year 1 of the survey.

${ }^{*} \mathrm{p}<0.1, * * \mathrm{p}<0.05, * * * \mathrm{p}<0.01, * * * * \mathrm{p}<0.001$ 
Exhibit 2: Health Insurance Status by the End of Year 2, Among Adults with Incomes 138-400\% of the Federal Poverty Level

\begin{tabular}{|c|c|c|c|c|c|c|c|c|c|c|}
\hline & \multicolumn{3}{|c|}{ Stable ESI in Year 1} & \multicolumn{3}{|c|}{ Previously-Uninsured in Year 1} & \multirow[b]{2}{*}{$\begin{array}{l}\text { Unadjusted } \\
\text { Difference in } \\
\text { Difference } \\
(\%) \\
\end{array}$} & & \multirow[b]{2}{*}{$\begin{array}{c}\text { Adjusted } \\
\text { Difference in } \\
\text { Difference } \\
(\%) \\
\end{array}$} & \\
\hline & $\begin{array}{c}\text { Pre-ACA } \\
(\%)\end{array}$ & $\begin{array}{l}\text { ACA- } \\
\text { affected } \\
(\%) \\
\end{array}$ & $\begin{array}{c}\text { Within } \\
\text { Group } \\
\text { Difference } \\
(\%) \\
\end{array}$ & $\begin{array}{l}\text { Pre- } \\
\text { ACA } \\
(\%) \\
\end{array}$ & $\begin{array}{l}\text { ACA- } \\
\text { affected } \\
(\%) \\
\end{array}$ & $\begin{array}{c}\text { Within } \\
\text { Group } \\
\text { Difference } \\
(\%) \\
\end{array}$ & & & & \\
\hline $\begin{array}{l}\text { Uninsured (\%) } \\
\text { Medicaid(\%) }\end{array}$ & $\begin{array}{l}6.7 \\
1.5\end{array}$ & $\begin{array}{l}2.3 \\
2.0\end{array}$ & $\begin{array}{c}-4.4 \\
0.5\end{array}$ & $\begin{array}{l}72.4 \\
4.5\end{array}$ & $\begin{array}{c}57.2 \\
7.6\end{array}$ & $\begin{array}{c}-15.2 \\
3.1\end{array}$ & $\begin{array}{c}-10.6 \% \\
2.6 \%\end{array}$ & $* * * *$ & $\begin{array}{c}-10.8 \% \\
2.5 \%\end{array}$ & $* * * *$ \\
\hline $\begin{array}{l}\text { Private, Employer } \\
\text { Sponsored(\%) } \\
\text { Private Non-ESI } \\
\text { (Includes Marketplace) }(\%)\end{array}$ & $\begin{array}{l}91.0 \\
1.0\end{array}$ & $\begin{array}{l}93.8 \\
1.8\end{array}$ & $\begin{array}{l}2.8 \\
0.8\end{array}$ & $\begin{array}{l}18.0 \\
2.2\end{array}$ & $\begin{array}{l}23.4 \\
8.9\end{array}$ & $\begin{array}{l}5.4 \\
6.7\end{array}$ & $\begin{array}{l}2.6 \% \\
5.8 \%\end{array}$ & $* * * *$ & $\begin{array}{l}2.8 \% \\
6.0 \%\end{array}$ & $* * * *$ \\
\hline Marketplace (\%) & N/A & 1.1 & N/A & N/A & 6.8 & $\mathrm{~N} / \mathrm{A}$ & $\mathrm{N} / \mathrm{A}$ & & $\mathrm{N} / \mathrm{A}$ & \\
\hline
\end{tabular}

Source: Authors analysis of MEPS longitudinal data, 2011-2014.

Notes: Insurance type is the self-reported insurance coverage in December of Year 2 of the longitudinal dataset. The stable ESI group was covered by employer-sponsored insurance for 12 months in year one of the dataset. The previously-uninsured group was

uninsured for $>$ or $=6$ months in year one of the dataset. The Pre-ACA cohort includes the 2011-2012 and 2012-2013 panels. The ACA-affected cohort includes the 2013-2014 panel. Difference-in-difference results represent estimates of the difference between the previously-uninsured and the previously-insured groups in the ACA-affected cohort (2013-2014) compared to the difference between the previously-uninsured and the previously-insured groups in the pre-ACA cohort (2011-2012 and 2012-2013).

$\mathrm{N} / \mathrm{A}=$ not applicable, because Marketplace coverage was not assessed in the MEPS (and did not exist) prior to 2014.

$* \mathrm{p}<0.1, * * \mathrm{p}<0.05, * * * \mathrm{p}<0.01, * * * * \mathrm{p}<0.001$ 


\section{Exhibit 3: Monthly Trends in Non-group Private Insurance Coverage}

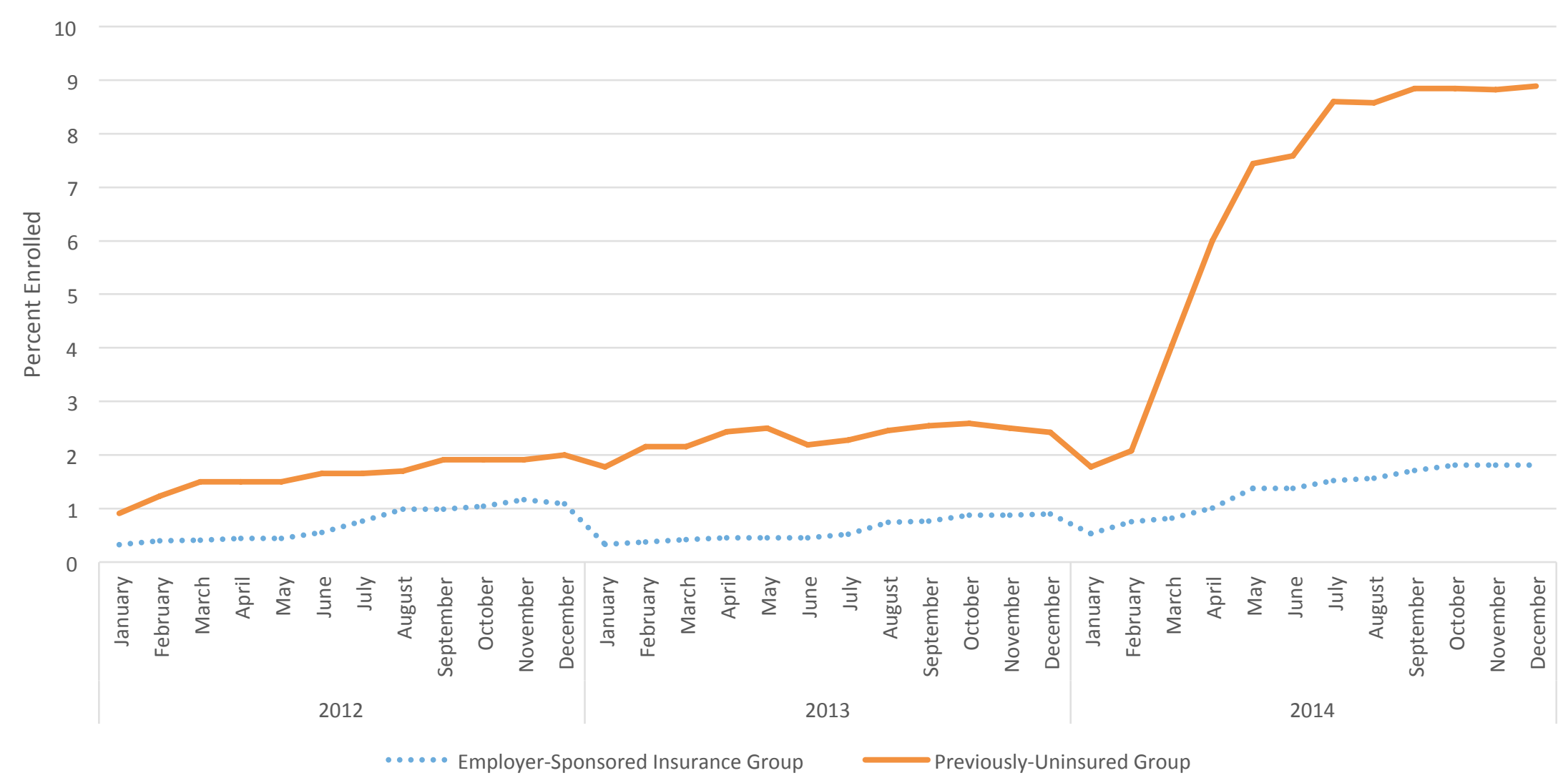

Source: Authors analysis of MEPS longitudinal data, 2011-2014.

Notes: Non-group coverage includes all private insurance that was not employer-sponsored, include ACA Marketplace plans. The stable ESI group was covered by employer-sponsored insurance for 12 months in year one of the dataset. The previously-uninsured group was uninsured for $>$ or $=6$ months in year one of the dataset. 


\section{Exhibit 4: Changes in Health-Care Related Outcomes Associated with the Affordable Care Act Among Adults with Incomes}

$138-400 \%$ of the Federal Poverty Level

\begin{tabular}{|c|c|c|c|c|c|c|c|c|c|c|c|}
\hline \multirow[b]{2}{*}{$\begin{array}{l}\text { Outcome (All } \\
\text { refer to Year } \\
2 \text { in the } \\
\text { survey) }\end{array}$} & \multicolumn{5}{|c|}{ Full Sample } & \multicolumn{3}{|c|}{ Low-Income (138-250\% FPL) } & \multicolumn{3}{|c|}{ Middle Income (251-400\% FPL) } \\
\hline & $\begin{array}{c}\text { Pre-ACA Mean } \\
\text { or Rate, } \\
\text { Previously- } \\
\text { Uninsured } \\
\text { Group }\end{array}$ & $\begin{array}{l}\text { Unadjusted } \\
\text { Diff-in-Diff } \\
\text { Estimate }\end{array}$ & & $\begin{array}{l}\text { Adjusted } \\
\text { Diff-in- } \\
\text { Diff } \\
\text { Estimate }\end{array}$ & & $\begin{array}{c}\text { Pre-ACA Mean } \\
\text { or Rate, } \\
\text { Previously- } \\
\text { Uninsured Group }\end{array}$ & $\begin{array}{c}\text { Adjusted } \\
\text { Diff-in-Diff } \\
\text { Estimate }\end{array}$ & & $\begin{array}{c}\text { Pre-ACA Mean } \\
\text { or Rate, } \\
\text { Previously- } \\
\text { Uninsured } \\
\text { Group }\end{array}$ & $\begin{array}{c}\text { Adjusted } \\
\text { Diff-in-Diff } \\
\text { Estimate }\end{array}$ & \\
\hline $\begin{array}{l}\text { Insured at the } \\
\text { end of year } 2\end{array}$ & $26.74 \%$ & $10.64 \%$ & $* * * *$ & $10.80 \%$ & $* * * *$ & $23.90 \%$ & $11.08 \%$ & $* * *$ & $29.70 \%$ & $13.16 \%$ & *** \\
\hline $\begin{array}{l}\text { Number of } \\
\text { Insured } \\
\text { months in } \\
\text { year } 2\end{array}$ & 2.8 & 1.02 & $* * * *$ & 1.04 & $* * * *$ & 2.73 & 0.96 & $* * *$ & 3.01 & 1.47 & $* * *$ \\
\hline $\begin{array}{l}\text { Unable to get } \\
\text { necessary } \\
\text { medical care } \\
(\%)\end{array}$ & $6.70 \%$ & $-1.90 \%$ & $*$ & $-1.93 \%$ & * & $6.70 \%$ & $-2.66 \%$ & $*$ & $6.70 \%$ & $-0.66 \%$ & \\
\hline $\begin{array}{l}\text { Delayed } \\
\text { prescription } \\
\text { meds (\%) }\end{array}$ & $3.70 \%$ & $-0.90 \%$ & & $-1.04 \%$ & & $3.30 \%$ & $0.10 \%$ & & $4.60 \%$ & $-3.30 \%$ & ** \\
\hline $\begin{array}{l}\text { Has a usual } \\
\text { source of care } \\
(\%)\end{array}$ & $47.30 \%$ & $0.90 \%$ & & $0.81 \%$ & & $45.40 \%$ & $-3.82 \%$ & & $50.80 \%$ & $8.62 \%$ & \\
\hline $\begin{array}{l}\text { Any OOP } \\
\text { Spending (\%) }\end{array}$ & $55.50 \%$ & $0.50 \%$ & & $0.09 \%$ & & $53.60 \%$ & $0.60 \%$ & & $59.10 \%$ & $-1.22 \%$ & \\
\hline $\begin{array}{l}\text { Any Medical } \\
\text { Spending (All } \\
\text { payers, \%) }\end{array}$ & $60.20 \%$ & $0.01 \%$ & & $-0.03 \%$ & & $59.10 \%$ & $1.78 \%$ & & $62.30 \%$ & $-3.38 \%$ & \\
\hline $\begin{array}{l}\text { Year } 2 \text { Mean } \\
\text { OOP } \\
\text { Spending } \\
\text { (Among Non- } \\
\text { zero } \\
\text { Spenders) }\end{array}$ & $\$ 227.41$ & $9.70 \%$ & & $9.70 \%$ & & $\$ 218.32$ & $19.19 \%$ & & $\$ 244.11$ & $-1.89 \%$ & \\
\hline
\end{tabular}


$4.30 \%$

$0.32 \%$

$2.50 \%$

$0.03 \%$ 
Source: Authors analysis of MEPS longitudinal data, 2011-2014.

Notes: All models use survey weighting and account for complex survey design. The stable ESI group was covered by employersponsored insurance for 12 months in year one of the dataset. The previously-uninsured group was uninsured for $>$ or $=6$ months in year one of the dataset. The Pre-ACA cohort includes the 2011-2012 and 2012-2013 panels. The ACA-affected cohort includes the 2013-2014 panel. Adjusted analyses control for age, sex, race, region, marital status, family size, birthplace outside the U.S., family income, and employment status. Age was transformed to a categorical variable, with five groupings: $18-24 ; 25-34 ; 35-44 ; 45-54$; and $<55$. Race was coded as Black, Hispanic, Asian, or White/other. Family size was converted to an ordinal categorical variable. OOP $=$ Out-of-Pocket.

${ }^{*} \mathrm{p}<0.1, * * \mathrm{p}<0.05, * * * \mathrm{p}<0.01, * * * * \mathrm{p}<0.001$ 


\section{Appendix A: Study Design}

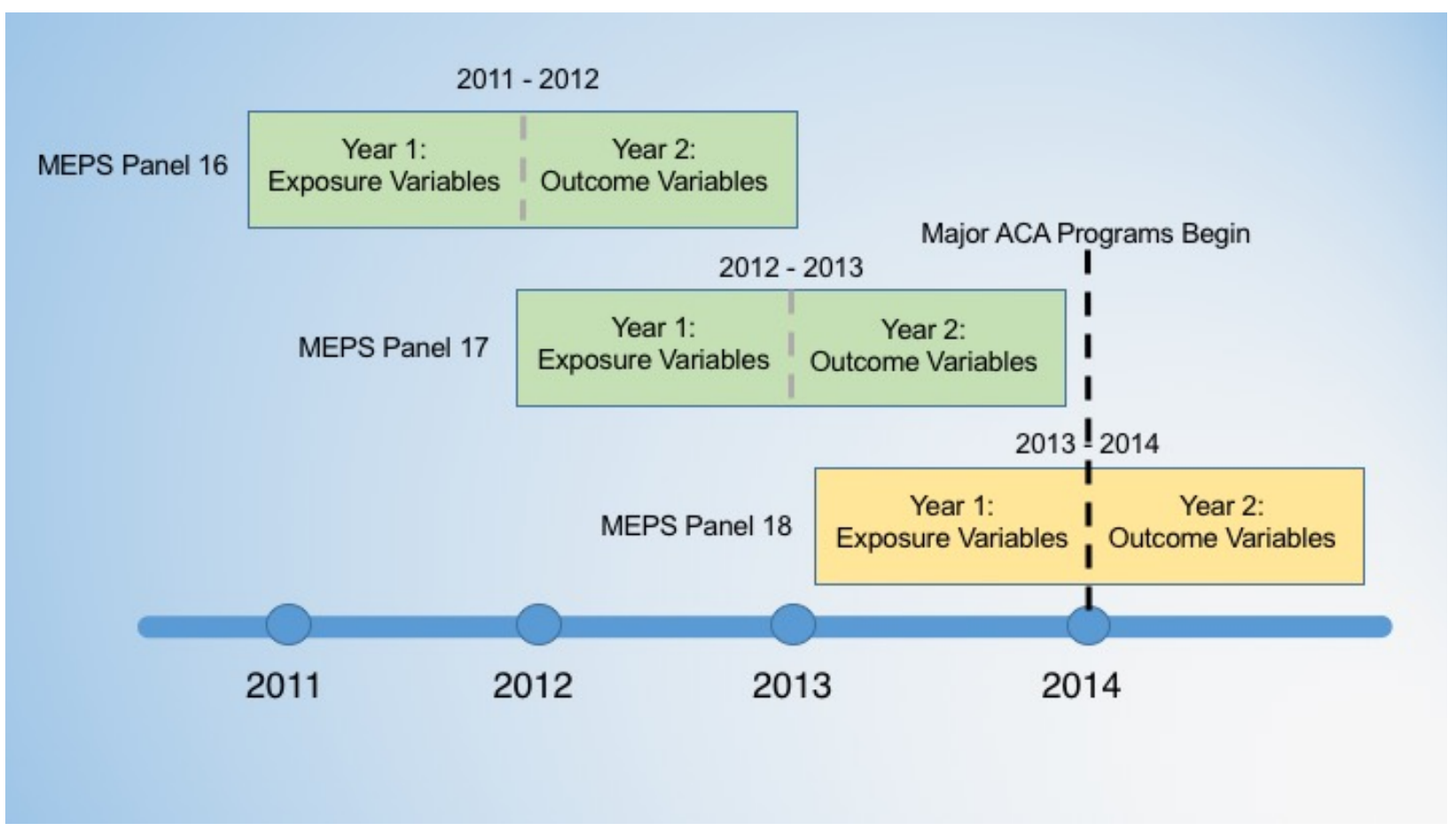

Source: Authors

Notes: Each panel is comprised of a cohort of non-elderly adults that were followed over the course of two years. In our study, inclusion criteria (age/income) and exposure variables (previously-insured via stable ESI or previously-uninsured) were drawn from Year 1 of each two-year panel, while outcome measures were assessed in Year 2. 


\section{Appendix B: Placebo Tests of Main Outcomes}

\begin{tabular}{|c|c|c|c|}
\hline Outcome (All refer to Year 2 in the survey) & $\begin{array}{l}\text { Adjusted Diff-in-diff } \\
\text { Estimate }\end{array}$ & $\begin{array}{c}\mathrm{p}- \\
\text { value }\end{array}$ & \\
\hline Number of uninsured months & 0.25 & 0.41 & \\
\hline Unable to get necessary care $(\%)$ & $0.84 \%$ & 0.6 & \\
\hline Delayed prescription meds (\%) & $-1.11 \%$ & 0.38 & \\
\hline Has a usual source of care $(\%)$ & $-4.08 \%$ & 0.16 & \\
\hline Any OOP Spending (\%) & $0.47 \%$ & 0.88 & \\
\hline Any Medical Spending (\%) & $-0.20 \%$ & 0.94 & \\
\hline $\begin{array}{l}\text { Percent Change in Mean Year } 2 \text { OOP } \\
\text { Spending (Among Non-zero Spenders,) } \\
\text { Percent Change in Mean Year } 2 \text { Total } \\
\text { Spending, all payers (Among Non-zero } \\
\text { Spenders, \%) }\end{array}$ & $14.66 \%$ & 0.34 & \\
\hline Avg Number of Outpatient Visits, & 0.01 & 0.98 & \\
\hline Avg Number of ER Visits & 0.04 & 0.16 & \\
\hline Avg Number of Prescription Drugs & 0.71 & 0.49 & \\
\hline Any Inpatient Admission (\%) & $0.15 \%$ & 0.91 & \\
\hline Any Preventive Visit (\%) & $-1.02 \%$ & 0.77 & \\
\hline Blood pressure check (\%) & $-0.69 \%$ & 0.82 & \\
\hline Cholesterol check $(\%)$ & $-5.82 \%$ & 0.08 & $*$ \\
\hline Poor/Fair Self-Reported Health (\%) & $0.96 \%$ & 0.67 & \\
\hline Diagnosis of high cholesterol in Year $2(\%)$ & $-1.92 \%$ & 0.47 & \\
\hline Diagnosis of diabetes in Year $2(\%)$ & $-1.70 \%$ & 0.21 & \\
\hline Diagnosis of hypertension in Year $2(\%)$ & $-0.89 \%$ & 0.73 & \\
\hline
\end{tabular}

Source: Authors analysis of MEPS longitudinal data, 2011-2013.

Notes: Placebo tests are designed to detect changes in the pre-ACA period and therefore model the difference-in-differences as if the ACA had been implemented in 2013. The pre-cohort is the 2011-2012 panel and the post-cohort is the 2012-2013 panel. These analyses control for age, sex, race, region, marital status, family size, family income, birthplace outside the US a and employment status. All models use survey weighting and account for complex survey design. The stable ESI group was covered by employer- 
sponsored insurance for 12 months in year one of the dataset. The previously-uninsured group was uninsured for $>$ or $=6$ months in year one of the dataset.

${ }^{*} \mathrm{p}<0.1, * * \mathrm{p}<0.05, * * * \mathrm{p}<0.01, * * * * \mathrm{p}<0.001$ 


\section{Appendix C: Pre- and Post-ACA Trends for Significant Outcomes:}
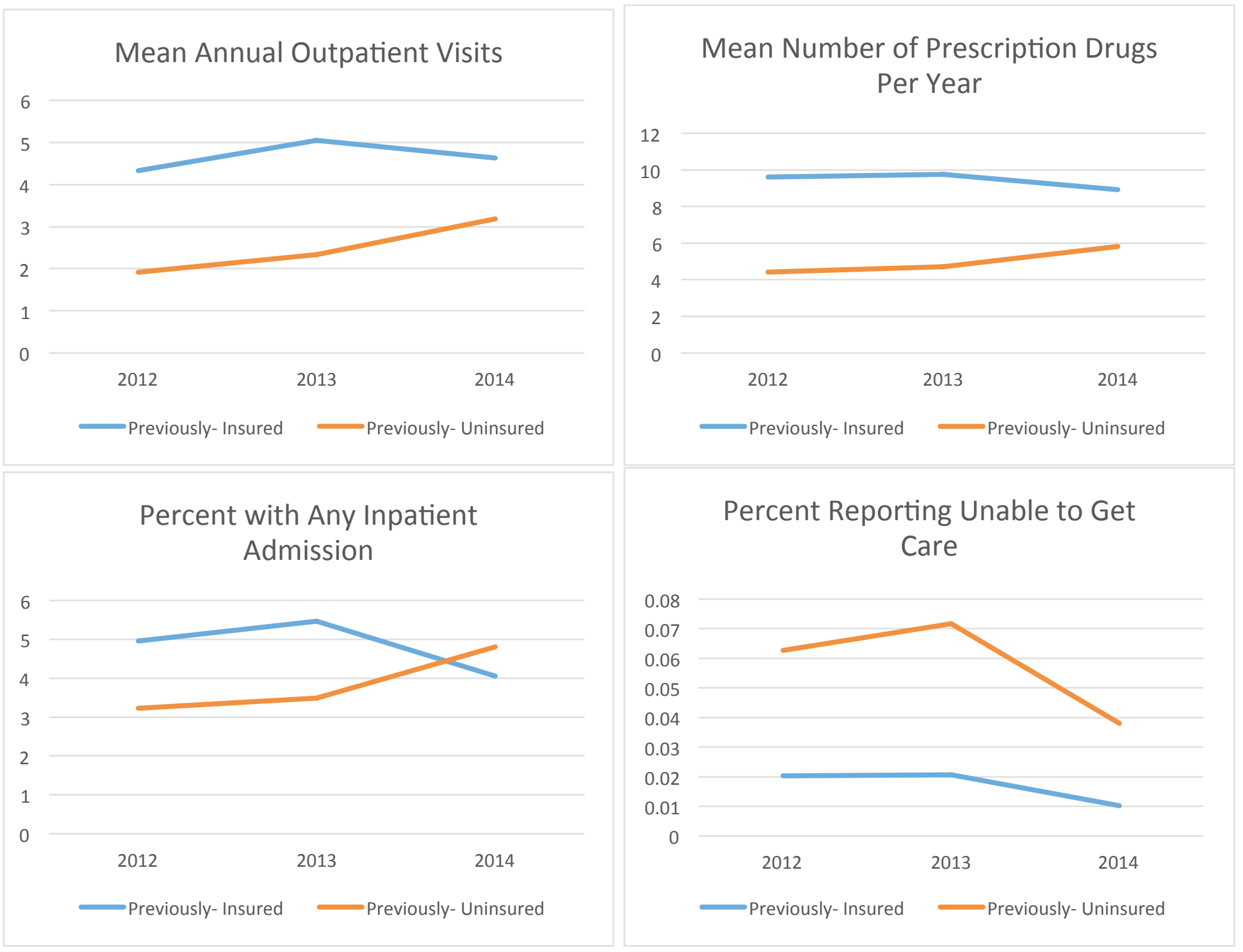


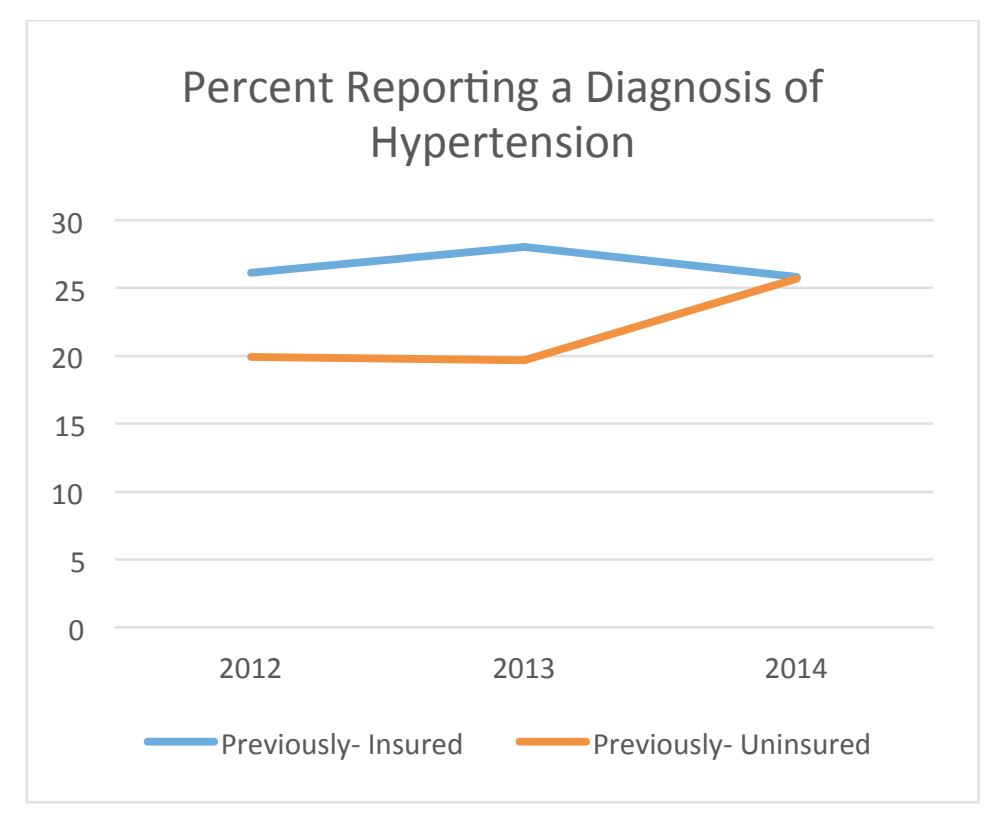




\section{Appendix D: Sensitivity analysis of Non-Elderly Adults with Incomes 138-400\% of Poverty Classified According to the MEPS Definition of Family}

\begin{tabular}{|c|c|c|c|c|}
\hline \multirow[b]{2}{*}{$\begin{array}{l}\text { Outcome (All refer to Year } 2 \text { in the } \\
\text { survey) }\end{array}$} & \multirow[b]{2}{*}{$\begin{array}{c}\text { Pre-ACA Mean or Rate, } \\
\text { Previously-Uninsured } \\
\text { Group }\end{array}$} & \multicolumn{2}{|l|}{ Adjusted } & \\
\hline & & Adjusted Diff-in-Diff Estimate & p-value & \\
\hline Number of uninsured months in year 2 & 9.66 & -1.12 & $<.0001$ & $* * * *$ \\
\hline Unable to get necessary med care $(\%)$ & $7.1 \%$ & $-2.4 \%$ & 0.03 & $* *$ \\
\hline Delayed prescription meds (\%) & $3.6 \%$ & $-0.7 \%$ & 0.47 & \\
\hline Has a usual source of care $(\%)$ & $46.5 \%$ & $1.0 \%$ & 0.70 & \\
\hline Year 2 Mean OOP Spending & $\$ 423.84$ & $19.8 \%$ & 0.26 & \\
\hline $\begin{array}{l}\text { Year } 2 \text { Mean Total Health Spending (all } \\
\text { payers) }\end{array}$ & $\$ 1,555.67$ & $21.4 \%$ & 0.32 & \\
\hline Avg Number of Outpatient Visits, & 2.04 & 1.31 & 0.02 & $* *$ \\
\hline Avg Number of ER Visits & 0.13 & -0.01 & 0.77 & \\
\hline Avg Number of Prescription Drugs & 4.43 & 1.64 & 0.08 & $*$ \\
\hline Any Inpatient Admission & $3.5 \%$ & 0.02 & 0.04 & $* *$ \\
\hline Any Preventive Visit & $38.0 \%$ & $-0.3 \%$ & 0.93 & \\
\hline Blood pressure check & $55.6 \%$ & $2.1 \%$ & 0.46 & \\
\hline Cholesterol check & $31.9 \%$ & $1.7 \%$ & 0.63 & \\
\hline Poor/Fair Self-Reported Health (\%) & $11.0 \%$ & $1.1 \%$ & 0.57 & \\
\hline Diagnosis of high cholesterol in Year 2 & $16.0 \%$ & $1.2 \%$ & 0.66 & \\
\hline Diagnosis of diabetes in Year 2 & $4.1 \%$ & $-0.4 \%$ & 0.76 & \\
\hline Diagnosis of hypertension in Year 2 & $19.7 \%$ & $4.1 \%$ & 0.06 & $*$ \\
\hline
\end{tabular}

Source: Authors analysis of MEPS longitudinal data, 2011-2014.

Notes: Adjusted analyses control for age, sex, race, region, marital status, family size, family income, and employment status. All models use survey weighting and account for complex survey design. The stable ESI group was covered by employer-sponsored 
insurance for 12 months in year one of the dataset. The previously-uninsured group was uninsured for $>$ or $=6$ months in year one of the dataset. The Pre-ACA cohort includes the 2011-2012 and 2012-2013 panels. The ACA-affected cohort includes the 2013-2014 panel. For spending figures, we took logarithms of dollar amounts to normalize the skewed distribution of spending and added one dollar to the measures of total and out-of-pocket spending (prior to log-transformation) so that those with zero spending would remain part the analysis.

${ }^{*} \mathrm{p}<0.1, * * \mathrm{p}<0.05, * * * \mathrm{p}<0.01, * * * * \mathrm{p}<0.001$ 